\title{
A Review on the Perpetrators of Child Abuse
}

\author{
K. R. Santhosh, Ph.D. a $^{*}$ \\ aHead of Academics, Arts and Social Sciences Division, Edutel Technologies (P) Ltd., Yeshwanthpur, India \\ *Corresponding author's email address: santhoshisme@gmail.com.
}

\section{A R T I C L E I N F O}

Received: 01-02-2016

Accepted: 21-02-2016

Available online: 27-02-2016

Keywords:

Child Abuse,

Perpetrator,

Vulnerability-Strength potentials,

Value strengths.

JEL Classification:

\begin{abstract}
A B S T R A C T
A review of the studies related to the perpetrators of child abuse revealed that each minimal unit of human being has the potential to perpetrate. Based on this, the present study aimed to comprehend the factors of vulnerability among the perpetrators of the child abuse. The study followed a method of investigating through the reviews of articles and research papers, on the issues of child abuse and perpetrations, published between 1994 and 2015, open source. The identified factors of vulnerability included age, family climate, personality, victim-to-victimizer cycle and opponent process hypothesis. However, identification of the factors shall not mislead anybody to consider the potential to be vulnerable or to be good as dichotomous, because it is multidimensional. Notably, the vulnerable individuals are a risk to the society, for it may generate a victim at any instant. There is a gap in the current literature regarding the methods that could be introduced to reduce the vulnerability to perpetrate. To fill this gap, first thing that has to be done is to have a shift in focus. Current literature is giving more focus on strengthening the potential victims. Instead, methods to intensify the value strengths of the perpetrators are to be focused here after. A model that may become the base of such an approach is designed and presented on the basis of Values in Action classification.

Key words: Perpetrators, factors of vulnerability, intervention, values in action
\end{abstract}

(C) 2016 The Authors. This is an open access article under the terms of the Creative Commons Attribution License 4.0, which allows use, distribution and reproduction in any medium, provided the original work is properly cited.

DOI: http://dx.doi.org/10.18533/rss.v1i3.25.

\section{$1.0 \quad$ Introduction}

Child abuse is a major social problem (Smallbone \& Wortley, 2001) to which, a child, if exposed, would have long lasting physical and psychological consequences. Any individual who causes or intentionally permits maltreatment of a child is a perpetrator (Children's Bureau, 2014). According to Wiehe (2003), perpetrators are self centered, narcissistic individuals who lack self confidence, impulse control and usually will be deficient in empathy. They were reported to be failures in their peer and marital relationships. Often, their existing relationships were found to be abusive, dysfunctional, or distressed. Many of the perpetrators were identified to be isolated and socially withdrawn. Some were found to be suffering from problems associated with mental health (Grayston \& De Luca, 1999).

Abusive deeds committed by perpetrators can broadly be classified in to two - (1) non-sexual and (2) sexual. Among these, most common, but less reported abuses are of non-sexual abuses. Among the non-sexual abuses, the most prominent mode of abuse is corporal punishment. Even in developed countries, two in five of the 
parents/guardians are in the practice of giving corporal punishments, especially smacking (Radford, et al., 2011). In the opinion of some of the parents, corporal punishments are useful (Bradshaw, et al., 2008) in disciplining children. However, some are in the habit of practicing it in more severe forms, for instance, smacking using hairbrush, belt, stick or a hard object. Many of them are less aware about the long term negative consequences of punishment that could even bring changes in victim's personality.

There are cultures in which parents become perpetrators thinking that disciplining through corporal punishment could help their children achieve social competence (Montgomery, 2006). Elders in such cultures generally have a tendency to see children to be incompetent and dependent (Montgomery, 2006). They demand children to be submissive to the elders. They share a prevailing attitude that they know best in guiding children (Lansdown, 2001). Isolated psychological reasons also may be there, for continuing practices of corporal punishments without giving much concern to the consequences. Convincing these perpetrators about the negative consequences of their act is not easy. For, they have reduced ability to take the perspective in others point of view (Wiehe2003). Further, they were less in warmth, compassion and concern for others, and were identified to have stressful interpersonal relationships.

\section{$2.0 \quad$ Literature review}

Numerous studies have conducted to identify the individuals that could be vulnerable to the perpetration. Gender related studies have indicated that the vulnerability is more prominent in males (Lucas et al, 2002). Inquiry of Flaherty (2006) through the confessions done by abusers of 41 children, hospitalized due to the injuries of victimization, revealed that $76 \%$ of the perpetrators were males. Schnitzer and Ewigman (2005) had also noted the higher involvement of male perpetrators in abusive acts. Even among the males, biological fathers of the victims seem to have a higher preponderance. Report by U.S.Department of Health and Human Services (2005), on the basis of the case-level data from the National Child Abuse and Neglect System (NCANDS) for 2002 , said that $51 \%$ of the perpetrators were biological fathers. Perpetrators' confession studies conducted by Flaherty (2006) designate that among the total sample, 56\% were the child's father. However, rather than alone, they will act in concert with others, such as mother, and the most probable punishment seems to be 'neglect'. Unlike other male perpetrators, biological fathers have least probability to be involved in sexual abuse (U.S. Department of Health and Human Services 2005).

Literature reveals that mothers can also be the perpetrators (U.S.Department of Health and Human Services 2005). As per the review done by Flaherty (2006) based on the information from the confessions of perpetrators, among 41 hospitalized children due to child abuse injuries, the child's mother was responsible for 34\%. According to Yampolskaya, Greenbaum, and Berson (2009), biological mothers with health problem tended to show more vulnerability to act as the perpetrator. As per the findings of Denov (2004) adult victims who had severe exposure to sexual abuse by their biological mothers experienced various psychosocial problems such as suicidal tendency, attempts to make self injury, substance abuse, depression, damaged relationship with women, rage, issues related to identity and self-concept, and sexual discomfort. However, compared to the reports on biological fathers, the probability to act as a perpetrator by the biological mothers is very less.

Going back to the reports of CAADA Research (2014), apart from fathers, who were reported to have a share of $73 \%$ in domestic abuse, $29 \%$ of the male perpetrators were mother's male partner (other than father). Male perpetrators who were not biological fathers have the tendency to act non-sexually, as well as, sexually (U.S. Department of Health and Human Services 2005). Categories included in this population are adoptive fathers, boyfriends of the mother, stepfathers, foster parents, other relatives, day care providers, or even friends (CAADA Research Report, 2014). Evidences regarding the higher tendency of male perpetrators with no biological relationship to be engaged in child sexual abuse could be seen in the study by Tyler and Cauce (2002) also,which contained interviews on 372 homeless and runaway adolescents.

Abuses by non-parental perpetrators may even become barbarous. Children living with unrelated adults indicated 50 times higher in risk of barbarous abuses, when compared to those living with biological parents (Schnitzer and Ewigman, 2005). The presence of such biologically unrelated caregiver is one of the strongest predictors of fatal child maltreatment (Yampolskaya, Greenbaum, and Berson, 2009). Even among the biologically unrelated caregivers, multiple problem perpetrators were 7 times and male perpetrators with domestic violence history were 12 times more vulnerable to have a deadly attack on children, when compared to biological parents. Abuse by female perpetrators too, may bring harmful and damaging consequences, especially if it is sexual abuse (Denov, 2004). As per the discovery of Rudin, Zalewski and Bodmer-Turner (1995), lone male and lone female-male perpetrators had no difference in the severity of abuse.The investigation of Vandiver 
and Kercher (2004) identified the prevalence of female sexual predators and young adult/child exploiters among 471 female sexual offenders, registed in Texas.

An intriguable finding by Rudin, Zalewski and Bodmer-Turner (1995) designated that, both female and male perpetrators have more proneness in abusing girls than boys. Higher tendency of the female offenders to abuse a female child has been noted by Grayston and De Luca (1999) also. Dysfunctional background of the family and experience of physical, emotional and sexual abuse during childhood or adolescence or adulthood, lower socioeconomic status, poorly paid employment and feminine stereotyped occupational role are some of the common familial characteristics shared by female perpetrators. Also, there are possibilities of having deviant arousal patterns, among some female sexual offenders, that would make them behave abusively from which some sexual gratification may be derived. Such abusive tendencies may also be the result of imprecise insights of motherly fondness and unfulfilled emotional needs (Grayston and De Luca, 1999).

The paper by Johnson (1989) describes that even a child can be the perpetrator of child abuse, and it can be sexual in nature. Sample of the study consisted of 13 child perpetrators, age ranged from 4 to 13, who were females. Force or coercion was used by these perpetrators to gain the obedience of the victims. 10 of them chose victims from their own family, and for the rest there had been lack of availability of family members. The average age of their first known perpetration was 6 years, 9 months. The mean age of the victims was 4 years, 4 months. The average number of victims was 3.5 with a range of 1 to 15 . They victimized two times more boys than girls. All of these child perpetrators were identified to be the past victims of sexual abuse. Most of them had the experiences of sexual molestation from the part of the family members itself. Some were the victims of physical abuse too. However, all these 13 child perpetrators were reported to be treated in a specially designed Support Program for Abuse-Reactive Kids (SPARK) at Children's Institute International of Los Angeles, California (Johnson 1989)

An overview of literature, thus throws light towards a reality which humanity may show frustration to accept. It is the reality that each minimal unit of human species has the potential to be the perpetrator. However, this potential is not activated in everyone. Hence, existence of certain factors that stimulates the vulnerability to act as a perpetrator shall be envisaged. What makes them vulnerable? Is it the yearning, which got distorted, to experience the motherly or fatherly affection (Grayston and De Luca 1999)? Does what Freud said about the instinctual urge to enjoy the pleasure of sex, and the satisfaction of libido getting activated here? What makes an individual vulnerable to act as a perpetrator is a complicated question that can only be answered on the basis of speculations. However, there are some information, even though not complete, regarding this in the available literature. The present study aims to comprehend the factors of vulnerability among the perpetrators of the child abuse. Further, it supplies appropriate recommendations on the basis of the comprehension.

\subsection{Method}

The study followed a method of investigating through the reviews of articles and research papers on the issues of child abuse and perpetrations. Open source articles and research papers, published between 1994 and 2015, relevent to the area of the study, are included in the review process. The following are the factors of vulnerability derived from the findings of different studies.

\subsection{Factors of vulnerability}

Different extrinsic and intrinsic triggering factors were found to be playing behind the act of perpetration. Extrinsic factors include demographic, social, familial and environmental factors. Factors associated with personal and interpersonal characteristics belong to the intrinsic.

\section{Age}

Age is one of the prominent demographic factors. According to Tyler and Cauce (2002), the average age range of the perpetrators would start from late 20s and would extend up to early 30s. Investigation done by Fehrenbach, Smith, Monastersky and Deisher (1986), based on a descriptive data $(\mathrm{N}=305)$ had revealed the proneness of adolescents to commit a series of sexual offenses. Even in the case of females, as Grayston and De Luca (1999) suggested, with a caution to not to generalize, that women perpetrators belong to an age range of 20s to 30s. However, before making a generalization, the recommendations by Esernio-Jenssen, Tai and Kodsi (2011), about the higher likelihood of Young perpetrator to confess and be convicted, should be taken for granted.

\section{Family Climate}


Pittman and Lee (2004) noted that types of abuse had varied with the changes in the factors associated with the family climate. Crying, victim being alone with the perpetrator, noon time etc. are some of the reported examples. Brewster, Nelson and Hymel (1998), in their study on the incidents of infanticides, observed that the infant-victim had been alone with the caretaker-perpetrator (in $86 \%$ of the cases), crying (in $58 \%$ of the cases), on the weekend (in $47 \%$ of the cases), during around noon time and at the home (in $71 \%$ of the cases). Crying, as a factor that could trigger abusive behaviour in the perpetrator was mentioned by Flaherty (2006) too. Being alone with a child can increase the risk of abusive behaviour in a perpetrator. For instance, father surrogates and biological fathers were more often perpetrators of both sexual and physical abuse when acting alone, but of neglect when acting with the mother (U.S. Department of Health and Human Services 2005). As per the report of Wiehe (2003), aversive behavior in children could provoke the perpetrators to physically and emotionally abuse them.

\section{Personality}

Intrinsic triggering factors include lack of self confidence, reduced impulse control, narcissism, self centeredness, deficiencies in empathy, other psycho-social problems etc. It is, again, Wiehe (2003)who reported that abusive parents are less in self-confidence and impulse control and more in narcissism. Further, they were reported to be deficient in empathy. They may be ego-centric too. Due to the ego-centricity, misbehaviours from the part of their children would be sensed as an insult to their authority. Child abuse risk were found to be positively associated with the symptoms of post-traumatic stress, dysphoria, self-dysfunction, drug abuse and alcoholism (Merrill, Crouch, Thomsen \& Guimond, 2004) in the perpetrator.

\section{Victim to Victimizer Cycle}

Brewster, Nelson and Hymel (1998) examined victim, perpetrator, family and incident variables in 32 cases of infanticide on the basis of available investigative records, birth, medical, autopsy etc. As per their identification, among the total sample, $23 \%$ of the caretaker-perpetrator had a history of abuse in childhood. Glasser, Kolvin, Campbell, Glasser, Leitch and Farrelly (2001) took retrospective clinical case note review of 843 subjects attending a specialist forensic psychotherapy centre. Results of the review indicated that abusive experiences in the past may contribute to the vulnerability to act as a perpetrator among men. The rate, in general, of having been a victim among these male perpetrators, was 35\%. In females, this tendency seems to be less. Of the 96 females in the sample, 43\% had been victims but only one was perpetrator (Brewster, Nelson and Hymel 1998). Still, that one among the females is an indication of the possibility. Hence, once being a victim can be considered as a predictor to become a perpetrator, later.

There is a presence of victim-to-victimizer cycle in many of the reported perpetration cases. Comparing the rates of sexual and non sexual abuses reported in 17 different studies, Jespersen, Lalumiere and Seto (2009) observed that adult sex offenders had a higher prevalence of sexual abuse history than non-sex offenders had. Identification of the victim with the abuser, as in the case of Stockholm syndrome, may be playing a role here. According to Jeremiah (2014), "traumatic bonding" similar to that in Stockholm syndrome could happen between the individual, who suffer from perpetual harassment or intimidation, and the perpetrator. During the time of abuse, the victim might be experiencing a helplessness feeling in such a way that none were there to show a way to escape (Fuselier, 1999). Gradually even a small move of kindness from the part of the perpetrator would instill a positive feeling in the mind of the victimized. Finally, identification of oneself in the position of perpetrator, considering one's own experience as reference, may be occurring.

The intrinsic factors such as lack of empathy and narcissism might have been developed in the perpetrator due to the victim to victimizer cycle. According to Goddard and Stanely (1994), many of the behavioural characteristics, usually observed in the terrorist-hostage literature, seems to have parallels in the behaviour of the perpetrator and the victimized child. These include similar personality characteristics, conditions associated with the violence, belief system in both the terrorist and the perpetrator and the defensive behavior implemented by both the hostage and the victimized child (Goddard \& Stanley, 1994). The powerful and the advantaged, exploiting the powerless, recognizing their weakness of the powerlessness and helplessness could be seen here. Later, powerless, may start respecting and loving the powerful and may repeat the same on another person who may be powerless to the previous powerless.

\section{Opponent Process Hypothesis}

Based on the confession studies (Flaherty 2006), it can be speculated that child abuse perpetrators who do not have previous severe abusive experience suffer from the guilty feeling for the abusive deeds, in their initial attempts. During the initiation of each attempt there may be an experience of approach avoidance conflict - 
individual's morale on one side and pleasure seeking on the other. Success in attempts makes the person continue perpetration sticking on to the pleasure and forgetting the morale. This opponent process may be happening in many of the child sexual abuse cases.

In non-sexual abuse cases, morale part of the process will be totally ignored. During corporal punishments, perpetrator's neglect of the morale is sublimated by the purpose of disciplining. Experience of abuses in the childhood by the perpetrator (example for victim - victimizer series or cycle) can be a supportive element for this neglect. Rationalizing the abusive behaviour in such a way that the perpetrator too had exposure to similar type of abuses in the past could reduce guilt feeling and conscientiousness in committing the deed. Such rationalizations may reach to its extremes and could result in severe assaulting abuses (Brewster, Nelson \& Hymel, 1998), which would later be simplified as accidents during the process of disciplining.

\subsection{Recommendation for a shift in focus}

The potential to perpetrate, and the fancy of the pleasure received from committing the abusive deed, is not activated in all the individuals. As Maslow and Rogers noted, this can be because of their innate tendency to be good and unconditional (Schultz \& Schultz, 2005). The strength, to maintain rational and healthy relationship with a child, and vulnerability, to submit oneself in the aggression (in corporal punishments) or sexual fantasy (in sexual abuses) and thereby to act as a perpetrator, in an individual cannot be evaluated in a dichotomous manner. It is multidimensional and individuals can position themselves in a continuum from the potential to be good to the potential to be vulnerable.

Scanning through the child abuse literature, majority of the studies and interventions can be seen concentrating on victims or would be victims. However, a victim can only be generated after an act done by a perpetrator. Until the perpetrator acts, there are no victims. If prevention and treatment interventions for child maltreatment are targeted primarily toward victims and would be victims, a large proportion of perpetrators will not benefit from these efforts (U.S. Department of Health and Human Services, 2005) Hence, studies, orientations and interventions aiming to avoid child abuse need a shift in focus. The Focus has to be kept more on the perpetrators than on victims. The objectives of the orientations and interventions should be aimed, not to reduce the tendency to perpetrate but, to activate the potential to keep up the value strengths.

\section{How can the interventions be?}

Hypothetically, news channel or news paper inquiries and reports about a "terrible" abuse, in order to enhance sympathy towards the victim or aggression towards the perpetrator, can never be considered as an orientation, nor it can be an intervention, to bring down the incidences of child abuse. Instead, it can act as reinforcement to the potential perpetrators to commit the deed. The reinforcing factor is the feeling of acceptance "not only me, but others too...; so I can also attempt it as a one-time error!" In other words, abusing the abuser can never help reduce abuse. A strength and value based approach has to be developed to help a person overcome the tendency of perpetration. Speculatively, the concept of value strengths (Peterson \& Seligman, 2004; Peterson, 2006) introduced by Positive Psychology pioneers could be a back up to such an approach. In the purview of value strengths, perpetrators may be those who suffer from the disorders of love, disorders of justice, disorders of temperance and disorders of transcendence. A theoretical skeleton, adapting the value strength framework to fix the reported behaviours of perpetrators follow.

In an individual who is suffering from the disorders of love, intimacy and the concept regarding the intimacy may be totally distorted (Peterson, 2006). This could be assumed to be happening in the perpetrators. Probably, they will be taking the risk of isolation or loneliness or may be suffering from emotional promiscuity. They might have the tendency to be kind. They might be feeling guilt in the initial attempts. But in the presence of the victim they are indifferent, cruel, or intrusive. They might have a weak social intelligence. While designing an intervention to make up the deficient dimensions that would be leading to the disorders of love, all these factors have to be considered. The value of love, that lies distorted in the perpetrator due to different unrealistic or irrational beliefs, could be attended and reestablished accurately with an appropriate psychotherapy.

If perpetrators are selfish and narcissist as Wiehe (2003) noted, they will be deficient in the values of citizenship in action. Perpetration may also be the result of partisanship and prejudice, which would indicate lack of fairness. Perpetrators who are despotic and disruptive will lack confidence to be a good leader. Objectification, the lack of concern to the rights and feelings of others (Out of the Fog, 2015), can be a factor that would be playing behind these disorders of justice. According to Zurbriggen (2013), objectification of other people will influence individuals to stand opposite to the principles of equality and respect for others. If the perpetrators are identified to be deficient in the values of citizenship, fairness etc, the focus of intervention shall be to enhance 
the value of justice in the individual. By enhancing the strength of justice, the ability of the individual in treating people according to the notions of fairness and justice can be strengthened.

A merciless and vengeful perpetrator will lack the capability of forgiveness. Reduced humility and modesty in the perpetrators would lead them to have footless self esteem or arrogance in their behaviour. Lack of prudence in the perpetrator may lead to sensation seeking or reckless behaviours. Depreciated capability of self regulation would result in self indulgence or impulsivity. Such deficiencies in any individual denote the disorder of temperament as it has been mentioned in Values in Action classification. Interventions may concentrate to enhance the capabilities of forgiveness or mercy, humility or modesty, prudence and self regulation in the individual.

Abuse happens because the appreciation of beauty is distorted in the perpetrators. They seems to be generally oblivious insensible to the feelings of the victims. Instead of gratitude, they have rugged individualism. Again, objectification (Zurbriggen 2013) can be playing behind their insensibility and ruggedness. Hence, hope, in them, would be sterile and surrounds around the object which satisfies the pleasure in the present. According to values in action classification, disorders of transcendence will make individuals deficient in appreciation of beauty or excellence, gratitude, hope, humour and spirituality. Perpetrators of corporal punishment shall be considered as pessimists, who were blind to the choices that enable child to be disciplined in healthy methods. However, interventions need not be designed to reduce the pessimism in them. The objectives of the intervention have to be to enhance the capacity to appreciate the beauty or excellence, to be thankful, to be hopeful, to be humorous and to be spiritual.

Certain studies show that interventions to overcome the tendency to be a perpetrator can be conducted successfully. One of the best examples is in the study by Olds, et al. (1997). They examined the long-term effects of a program of prenatal and early childhood home visitation by nurses on women's life course and child abuse and neglect using randomized trial design in a sample of 400 consecutive pregnant women with no previous live births enrolled and in which 324 participated in a follow-up study when their children were 15 years old. As per the results, prenatal and early childhood home visitation by nurses reduced later child abuse and neglect from the part of the mother. Latest data from CAADA's adult Insights National Dataset 2012-13 for adult victims of abuse show that $69 \%$ of domestic abuse ceased at the point of case closure after support from an IDVA (CAADA Research Report, 2014).

\subsection{Conclusion}

Definitely, here, the previous doubt may be pervading "How can a perpetrator be identified?"

The answer, "Take a mirror and look in to it" may make anybody frustrated. A repeat, "each individual, the minimal unit of human species, has the potential to be the perpetrator, if not the individual has proneness towards goodness potentiality' may not help to satisfy many. Hence, to fill the gap, a measurement shall be developed to fix the individual between the "potential to be good to the potential to be vulnerable" continuum. Each individual shall be given an opportunity to submit themselves to undergo the measure. Anybody who finds themselves prone towards the vulnerable end of the continuum shall show the readiness to undergo an intervention that will enhance the value strengths.

\section{References}

Boehnke, K., \&Hadjar, A. (2001). Authoritarianism. In C. Spielberger, Encyclopedia of Applied Psychology (pp. 251-255). Florida: Elsevier.

Bradshaw, P., Cunningham-Burley, S., Dobbie, F., MacGregor, A., Marryat, L., Ormston, R., et al. (2008). Growing up in Scotland: Sweep 2 Overview Report. Edinburgh: Scottisth Government.

Brewster, A. L., Nelson, J. P., \&Hymel, K. P. (1998). Victim, perpetrator, family, and incident characteristics of 32 infant maltreatment deaths in the United States Air Force. Child abuse andneglect, 22 (2), 91-101. http://dx.doi.org/10.1016/S0145-2134(97)00132-4.

CAADA Research Report. (2014, February). In plain sight: The evidence from children exposed to domestic abuse. Retrieved February 12, 2015, from Coordinated action against domestic abuse: http://www.caada.org.uk/documents/In_plain_sight_the_evidence_from_children_exposed_to_domestic_ab use.pdf.

Children's Bureau. (2014). Definitions of Child Abuse \& Neglect. Retrieved 3 25, 2015, from Child Welfare Information Gateway: https://www.childwelfare.gov/pubPDFs/define.pdf. 
Denov, M. S. (2004). The Long-Term Effects of Child Sexual Abuse by Female Perpetrators: A Qualitative Study of Male and Female Victims. Journal of Interpersonal Violence, 19 (10), 1137-1156. http://dx.doi.org/10.1177/0886260504269093.

Esernio-Jenssen, D., Tai, J., \&Kodsi, S. (2011). Abusive Head Trauma in Children: A Comparison of Male and Female Perpetrators. Pediatrics , 127 (4), 649-657. http://dx.doi.org/10.1542/peds.2010-1770.

Fehrenbach, P. A., Smith, W., Monastersky, C., \&Deisher, R. W. (1986). Adolescent sexual offenders: Offender and offense characteristics. American Journal of Orthopsychiatry, $56 \quad$ (2), 225-233. http://dx.doi.org/10.1111/j.1939-0025.1986.tb02722.x.

Flaherty, E. G. (2006). Analysis of caretaker histories in abuse: comparing initial histories with subsequent confessions. Child Abuse \&Neglect, 30 (7), 789-798. http://dx.doi.org/10.1016/j.chiabu.2005.12.008

Fuselier, G. D. (1999). Placing the Stockholm Syndrome in Perspective. Retrieved March 11, 2015, from www.au.af.mil/au/awc/awcgate/fbi/stockholm_syndrome.pdf.

Glasser, M., Kolvin, I., Campbell, D., Glasser, A., Leitch, I., \&Farrelly, S. (2001). Cycle of child sexual abuse: links between being a victim and becoming a perpetrator. The British Journal of Psychiatry, 179, $482-494$. http://dx.doi.org/10.1192/bjp.179.6.482.

Goddard, C. R., \& Stanley, J. R. (1994). Viewing the Abusive Parent and the Abused Child as Captor and Hostage:The Application of Hostage Theory to the Effects of Child Abuse. Jounral of Interpersonal Violence, 9 (2), 258-269. http://dx.doi.org/10.1177/088626094009002008.

Grayston, A. D., \& De Luca, R. V. (1999). Female Perpetrators of Child Sexual Abuse: A Review of the Clinical and Empirical Literature. Aggression and Violent Behaviour, 4 (1), 93-106. http://dx.doi.org/10.1016/S13591789(98)00014-7.

Jeremiah, S. M. (2014). Applying the Stockholm syndrome Phenomenon in Osofisan'sMorountodunto Leadership in Africa. Journal of Humanities \& Social Sciences, 19 (5), 53-59.

Jespersen, A. F., Lalumiere, M. L., \&Seto, M. C. (2009). Sexual Abuse History Among Adult Sex Offenders and NonSex Offenders: A Meta-Analysis. Child Abuse and Neglect: The International Journal, 33 (3), $179-192$. http://dx.doi.org/10.1016/j.chiabu.2008.07.004.

Johnson, T. C. (1989). Female child perpetrators: Children who molest other children. Child Abuse \& Neglect, 13 (4), 571-585. http://dx.doi.org/10.1016/0145-2134(89)90061-6.

Lansdown, G. (2001). Promoting Children's Participation in Democratic Decision Making. Florence, Italy: Unicef.

Lucas, D. R., Wezner, K. C., Milner, J. S., McCanne, T. R., Harris, I. N., Monroe-Posey, C., et al. (2002). Victim, perpetrator, family, and incident characteristics of infant and child homicide in the United States Air Force. Child Abuse \& Neglect, 26 (2), 167-186. http://dx.doi.org/10.1016/S0145-2134(01)00315-5.

Mahrer, A. R. (1995). The complete guide to Experiential Psychotherapy. New York: Wiley \& Sons, Inc.

Merrill, L. L., Crouch, J. L., Thomsen, C. J., \&Guimond, J. M. (2004). Risk for intimate partner violence and child physical abuse: psychosocial characteristics of multirisk male and female Navy recruits. Child maltreatment: journal of the American Professional Society on the Abuse of Children, 9, 18-29. http://dx.doi.org/10.1177/1077559503260852.

Montgomery, H. (2006, August 17). Different Cultures, Different Childhoods. Retrieved March 21, 2014, from OpenLearn: The home of free learning from the Open University: http://www.open.edu/openlearn/history-the-arts/history/different-cultures-different.

Out of the Fog. (2015). Objectification. Retrieved March 13, 2015, from Information and Support for those with a family member or loved one who suffers from a personality disorder: outofthefog.net/CommonBehaviors/objectification.html.

Olds, D. L., Eckenrode, J., Henderson, C. R., Kitzman, H., Powers, J., Cole, R., et al. (1997). Long-term Effects of Home Visitation on Maternal Life Course and Child Abuse and Neglect: Fifteen-Year Follow-up of a Randomized Trial. Journal of American Medica Association, 278 (8), 637-643. http://dx.doi.org/10.1001/jama.278.8.637.

Peterson, C., \& Seligman, M. E. (2004). Character, Strengths and Virtues: A Handbook and Classification. New York: Oxford University Press.

Peterson, C. (2006). The Values in Action (VIA) Classification of Strengths. In M. Csikszentmihalyi, \& I. S. Csikszentmihalyi (Eds.), A Life Worth Living: Contributions to Positive Psychology (pp. 29-48). New York: Oxford University Press.

Pittman, J. F., \& Lee, C.-Y. S. (2004). Comparing different types of child abuse and spouse abuse offenders. Violence and Victims, 19, 137-156. http://dx.doi.org/10.1891/vivi.19.2.137.64098.

Radford, L., Corral, S., Bradley, C., Fisher, H., Bassett, C., Howat, N., et al. (2011). Child Abuse and Neglect in the UK Today. London: NSPCC.

Rudin, M. M., Zalewski, C., \&Bodmer-Turner, J. (1995). Characteristics of child sexual abuse victims according to perpetrator gender. Child Abuse \& Neglect, 19 (8), 963-973. http://dx.doi.org/10.1016/01452134(95)00058-G.

Schnitzer, P. G., \&Ewigman, B. G. (2005). Child Deaths Resulting From Inflicted Injuries: Household Risk Factors and Perpetrator Characteristics. Pediatrics, 116 (5), 687-693. http://dx.doi.org/10.1542/peds.2005-0296 
Schultz, D. P., \& Schultz, S. E. (2005). Theories of Personality. Belmont: Wadsworth.

Smallbone, S. W., \&Wortley, R. K. (2001). Child Sexual Abuse: Offender characteristics and Modus Operandi. Canberra: Australian Institute of Criminology.

Tyler, K. A., \&Cauce, A. M. (2002). Perpetrators of Early Physical and Sexual Abuse Among Homeless and Runaway Adolescents. Child Abuse and Neglect, 26, 1261-1274. http://dx.doi.org/10.1016/S01452134(02)00413-1.

U.S. Department of Health and Human Services. (2005). Male perpetrators of child maltreatment: Findings from NCANDS. New York: Office of the Assistant Secretary for Planning and Evaluation.

Vandiver, D. M., \&Kercher, G. (2004). Offender and Victim Characteristics of Registered Female Sexual Offenders in Texas: A Proposed Typology of Female Sexual Offenders. Sexual Abuse: A Journal of Research and Treatment, 16 (2), 121-137. http://dx.doi.org/10.1177/107906320401600203.

Wiehe, V. R. (2003). Empathy and narcissism in a sample of child abuse perpetrators and a comparison sample of foster parents. Child abuse \& Neglect, 27 (5), 541-555. http://dx.doi.org/10.1016/S01452134(03)00034-6.

Yampolskaya, S., Greenbaum, P. E., \&Berson, I. R. (2009). Profiles of Child Maltreatment Perpetrators and Risk for Fatal Assault: A Latent Class Analysis. Journal of Family Violence, 24 (5), 337-348. http://dx.doi.org/10.1007/s10896-009-9233-8.

Zurbriggen, E. L. (2013). Special Thematic Section on "Societal Change": Objectification, Self Objectification and Societal Change. Journal of Social and Political Psychology, 1 (1), 188-215. http://dx.doi.org/10.5964/jspp.v1i1.94. 